Pesq. Vet. Bras. 30(4):321-327, abril 2010

\title{
Avaliação das fibras colágenas de meniscos frescos e preservados em glicerina: estudo experimental em coelhos (Oryctolagus cuniculus) ${ }^{1}$
}

\author{
Liana M. Vilela ${ }^{2}$, Ricardo J. Del Carlo3* ${ }^{3 *}$ João Carlos P. da Silva ${ }^{4}$, Sérgio Luís \\ P. Da Matta ${ }^{5}$, Mauricio Correia D. Rodrigues ${ }^{2}$ e Amanda Maria S. Reis ${ }^{6}$
}

\begin{abstract}
Vilela L.M., Del Carlo R.J., Silva J.C.P., Matta S.L.P. \& Reis A.M.S. 2009. [Evaluation of the collagen fibers of the fresh meniscus and the meniscuses preserved in glycerine: Experimental study in rabbits (Oryctolagus cuniculus).] Avaliação das fibras colágenas de meniscos frescos e preservados em glicerina: estudo experimental em coelhos (Oryctolagus cuniculus). Pesquisa Veterinária Brasileira 30(4):321-327. Departamento de Veterinária, Universidade Federal de Viçosa, 36570-000 Viçosa, MG, Brazil. E-mail: ricarlo@ufv.br

In the present study was evaluated the effect of $98 \%$ glycerin on the collagen fibers, tissue architecture and size of medial meniscuses of New Zealand rabbits. The animals were separated into three groups: (1) Group MF of fresh meniscus, (2) Group MG of meniscus preserved in glycerin for 30 days, and (3) Group MR of meniscus preserved in glycerin for 30 days and rehydrated in $\mathrm{NaCl} 0.9 \%$ for 12 hours. Histological sections were stained with sirius red for identification of collagen types, which were examined with a polarized light microscope. The total collagen concentration and the fiber arrangement were evaluated. Group MF presented higher Type I collagen concentration and lower Type III collagen concentration when compared with Group MG and MR. This fact is due to the water loss and consequent reduction in size and subsequent retraction of the collagen fibers of the meniscus from these groups, caused by dehydration. This may have occurred because those Type I fibers, thicker and in larger quantities, become more evident than Type III collagen fibers, which are more slender and fragile (fibrils). In the three groups studied, the collagen fibers presented themselves in a circumference form, interposed by radially oriented fibers. All of the meniscuses from Group MF presented fibers arranged obliquely, while in the treated groups, a slight disorganization of collagen fibers could be observed in some areas, what corresponds to $42.8 \%$ and $14.3 \%$ of the meniscuses, respectively. The MG group presented a significant decrease $(p<0.05)$ in size if compared with the MF group. In the MR group, $85.7 \%$ of the meniscuses went back to the original size after rehydratation. The $98 \%$ glycerin is effective in preserving the meniscus, following rehydratation, maintaining size, structural architecture, integrity and percentage of collagen of the meniscus preserved similar to the fresh one.
\end{abstract}

INDEX TERMS: Allograft, articular cartilage, meniscus.

\footnotetext{
${ }^{1}$ Recebido em 23 de abril de 2009.

Aceito para publicação em 8 de setembro de 2009.

2 Pós-Graduando, Programa de Pós-Graduação em Medicina Veterinária, Universidade Federal de Viçosa (UFV), Viçosa, MG 36570-000, Brasil.

${ }^{3}$ Departamento de Veterinária (DVT), UFV, Viçosa, MG. *Autor para correspondência: ricarlo@ufv.br

${ }^{4}$ Setor de Patologia, DVT, UFV, Viçosa, MG.

${ }^{5}$ Departamento de Biologia Geral, UFV, Viçosa, MG.

${ }^{6}$ Graduando, DVT, UFV, Viçosa, MG.
}

RESUMO.- No presente estudo foi avaliado o efeito da glicerina $98 \%$ sobre as fibras colágenas, arquitetura tecidual e o tamanho de meniscos mediais de coelhos da raça Nova Zelândia. Os meniscos foram separados em três grupos: (1) Grupo MF com meniscos frescos (grupo controle), (2) Grupo MG com meniscos preservados em glicerina $98 \%$ por 30 dias, e (3) Grupo MR com meniscos preservados em glicerina $98 \%$ por 30 dias e reidratados em $\mathrm{NaCl}$ 0,9\%, por 12 horas. Os cortes histológicos fo- 
ram corados com sirius red para identificação dos tipos de colágenos e observados em microscópio de luz polarizada, avaliando-se a concentração total de colágeno Tipo I e III e a disposição das fibras. Os meniscos frescos apresentaram significativamente maior concentração de fibras colágenas Tipo I e menor concentração de fibras colágenas Tipo III que os meniscos preservados (MG e MR); isto ocorreu devido à perda de água e conseqüente redução do tamanho dos meniscos e retração das fibras colágenas dos meniscos dos Grupos MG e MR; isto pode ter feito com que as fibras Tipo I, mais espessas e em maior quantidade, se tornassem mais evidentes do que as fibras colágenas Tipo III, que são mais delgadas e frágeis (fibrilas). Nos três grupos estudados, as fibras colágenas apresentaram-se de forma circunferencial, interpostas por fibras orientadas radialmente. Entretanto, nos grupos tratados (MG e MR) foi observado, em pequenas áreas, leve desorganização das fibras colágenas, o que correspondeu a $42,8 \%$ e $14,3 \%$ dos meniscos, respectivamente. O grupo de meniscos em glicerina apresentou redução significativa $(p<0,05)$ no tamanho em relação ao Grupo MF. No Grupo MR, $85,7 \%$ dos meniscos retornaram ao seu tamanho inicial após a reidratação. A glicerina $98 \%$ é eficaz na preservação de meniscos, mantendo o tamanho, a arquitetura estrutural, a integridade e percentagem do colágeno dos meniscos preservados semelhante à de meniscos frescos, desde que sejam reidratados em $\mathrm{NaCl}$ 0,9\% após preservação.

TERMOS DE INDEXAÇÃO: Aloenxerto, cartilagem articular, menisco.

\section{INTRODUÇÃO}

Os meniscos apresentam a função de transmissão de cargas, absorção de choques, contribuem para a estabilidade articular durante a flexão e extensão, promovem a congruência entre o fêmur e a tíbia, e auxiliam na lubrificação da articulação (Hulse \& Johnson 2002, Vasseur 2007). A capacidade do menisco em realizar funções mecânicas depende de sua estrutura anatômica e de sua propriedade material, que são determinadas pela composição bioquímica, além da interação dos seus constituintes como água, proteoglicanos e colágeno (Paiva 2006).

Os meniscos são fibrocartilagens compostas principalmente de colágeno tipo I, que representa cerca de $80 \%$ do conteúdo total, sendo os $20 \%$ restantes constituídos por fibras colágenas dos Tipos II, III, V e VI, proteoglicanos, células e pequena quantidade de fibras elásticas (McDevitt \& Webber 1990, McBride \& Clancy 2000, Jackson et al. 2001, Buma et al. 2004, Paiva 2006).

As fibras colágenas do menisco são orientadas, principalmente, de maneira circunferencial, entrelaçadas por fibras orientadas radialmente, que partem da superfície do menisco em direção às suas camadas mais profundas (Rijk 2004, Paiva 2006). Esse tipo de organização contribui para a manutenção de propriedades mecânicas como força tênsil e rigidez (Paiva 2006).
Somer \& Somer (1983) em um estudo com cães, analisaram os meniscos mediais e laterais com especial consideração às fibras colágenas e elásticas, elementos celulares, substâncias intercelulares e vasos sanguíneos; e não encontraram diferença significativa na estrutura histológica entre os meniscos lateral e medial.

As extremidades dos meniscos são chamadas de cornos e o segmento do menisco que se estende entre os cornos é denominado corpo do menisco (Somer \& Somer 1983, Vasseur 2007). O colágeno dos cornos está organizado em feixes delicados, separados por septos de tecido conjuntivo frouxo. O colágeno do corpo encontra-se disposto em um padrão de espinha de peixe (Vasseur 2007).

A lesão dos meniscos ocorre quando sua fibrocartilagem fica exposta à tensão ou pressão anormal, comumente quando a articulação com sustentação do peso fica submetida a movimentos combinados de flexão e rotação, ou de extensão e rotação (Arnoczky 1996, De Groott et al. 1996, Torres et al. 2006). A fibrocartilagem demonstra degeneração mucóide da matriz cartilaginosa e fragmentação dos feixes de colágeno que, diante da tensão contínua, produzem lesões de clivagem horizontal (Arnoczky 1996). A meniscectomia total e a substituição dos meniscos por aloenxertos são procedimentos freqüentemente realizados quando outras opções para reparo ou reconstrução do menisco não puderem ser utilizadas (Rijk 2004, Reckers et al. 2005)

Um meio de preservação frequentemente utilizado para próteses biológicas é a glicerina a $98 \%$, mantida em temperatura ambiente. Ela apresenta como vantagens o baixo custo e propriedade antisséptica, atuando como bactericida e fungicida (Alvarenga 1992, Del Carlo et al. 1999, Filgueiras et al. 2007), além de reduzir a antigenicidade do tecido nela conservado e preservar a textura (Pigossi 1967). Guimarães et al. (2007) em um estudo com membranas biológicas preservadas em glicerina a 98\% por diferentes períodos, relataram a ocorrência de retração das fibras colágenas e desorganização tecidual, mas com mínimas alterações na integridade tecidual.

O objetivo deste estudo foi quantificar os tipos de colágeno, avaliar a disposição das fibras e o tamanho de meniscos de coelhos, tantos frescos como preservados em glicerina $98 \%$ por 30 dias, seguido de reidratação em solução salina por 12 horas, para futura utilização, como aloenxertos, após meniscectomia.

\section{MATERIAL E MÉTODOS}

A metodologia foi aprovada pela comissão de Ética do Departamento de Veterinária, da Universidade Federal de Viçosa (UFV), sob parecer número 89/2007. Foram utilizados 21 meniscos mediais, provenientes de joelhos de 11 coelhos albinos da raça Nova Zelândia, o $22^{\circ}$ menisco foi desprezado. Os animais tinham entre três e quatro meses de idade e peso médio de $3 \mathrm{~kg}$, sendo oriundos de criação comercial da cunicultura do Departamento de Zootecnia, Universidade Federal de Viçosa (UFV). A retirada dos meniscos foi realizada 
imediatamente após o abate e em condições de limpeza, mas sem rigores de assepsia.

Por intermédio de instrumental cirúrgico foi realizada incisão transversal na cápsula articular envolvendo o ligamento colateral medial. Um esforço em valgo foi o suficiente para facilitar a visualização e o acesso ao menisco medial. Foram seccionados os ligamentos cruzado cranial e caudal, meniscotibial cranial e caudal, meniscocapsulares e o intermeniscal, realizando a coleta dos meniscos. Foram removidos restos de ligamentos e gordura aderidos aos meniscos mediais coletados, o tamanho de cada menisco foi mensurado com paquímetro, registrando a medida de seu eixo maior. Os meniscos foram acondicionados em frascos individuais de vidro, identificados e distribuídos aleatoriamente em três grupos, com sete meniscos cada. $O$ grupo MF foi composto por meniscos frescos (recém-colhidos), e correspondeu ao grupo controle, estes meniscos foram imersos em formalina 10\%, tamponada, por 24 horas.

O Grupo MG foi composto por meniscos acondicionados em frascos com a proporção glicerina 98\%/menisco de 20:1, por 30 dias, em temperatura ambiente. Após esse período, os meniscos foram retirados da glicerina, mensurados e imersos em formalina $10 \%$ tamponada, por 24 horas. O Grupo MR foi composto por meniscos que foram imersos em glicerina $98 \%$, por 30 dias, em temperatura ambiente. Logo após o período de preservação, os meniscos foram mensurados e imersos em solução salina ( $\mathrm{NaCl}$ 0,9\%), durante 12 horas, para reidratação, simulando condições a que seriam submetidos nos períodos pré e trans-operatório. Em seguida, foram imersos em formalina $10 \%$ por 24 horas, para processamento histológico.

Após a fixação o material foi processado para inclusão em parafina seguindo as seguintes etapas: desidratação em série crescente de etanol $(70 \%, 80 \%, 90 \%$ e $100 \%)$, diafanização (xilol I, II e III) e infiltração (parafina histológica $56^{\circ} \mathrm{I}$, II, III) em estufa, sendo depois incluídos em parafina, em temperatura ambiente. As secções obtidas foram coradas pelo método de picrosirius red (sirius red + ácido pícrico) (Montes e Junqueira, 1991), para identificação e quantificação das fibras colágenas Tipo I e Tipo III. O primeiro aparece na forma de fibras espessas, amareladas ou avermelhadas, muito birrefringentes e o segundo com birrefringência fraca, caracterizado por fibrilas esverdeadas, quando examinados sob luz polarizada.

Cada preparação, corada pelo picrosirius, foi observada em microscópio de luz polarizada (Olympus AX-70), que transmite as imagens a um microcomputador equipado com o software Spot Basic 3.5.9, para identificação dos tipos de colágeno e da disposição das fibras colágenas nos três grupos experimentais.

A partir de cada amostra foram registradas cinco imagens de diferentes campos, de cada parte do menisco (corpo e cornos), num total de 15 imagens por lâmina, utilizando-se objetiva de 10x, de maneira que toda a extensão do menisco fosse fotografada. Depois de capturadas, as imagens foram analisadas pelo sistema de análise de imagens (Image ProPlus ${ }^{\circledR} 4.5$ ) (Fig.1), com a finalidade de avaliar a proporção de fibras colágenas dos Tipos I e III. Utilizou-se uma grade com 100 interseções sobre a imagem analisada, onde foram contados os pontos sobre a cor vermelha, Iaranja ou amarela, representando fibras colágenas do Tipo I, sobre a cor verde, representando fibras colágenas do Tipo III e sobre a cor preta, representando as regiões onde não foram encontradas qualquer tipo de fibra. Estabeleceu-se então a percentagem de cada cor e assim de cada tipo de fibra colágena, sendo a disposição das fibras colágenas classificada ainda como ordenada ou não.

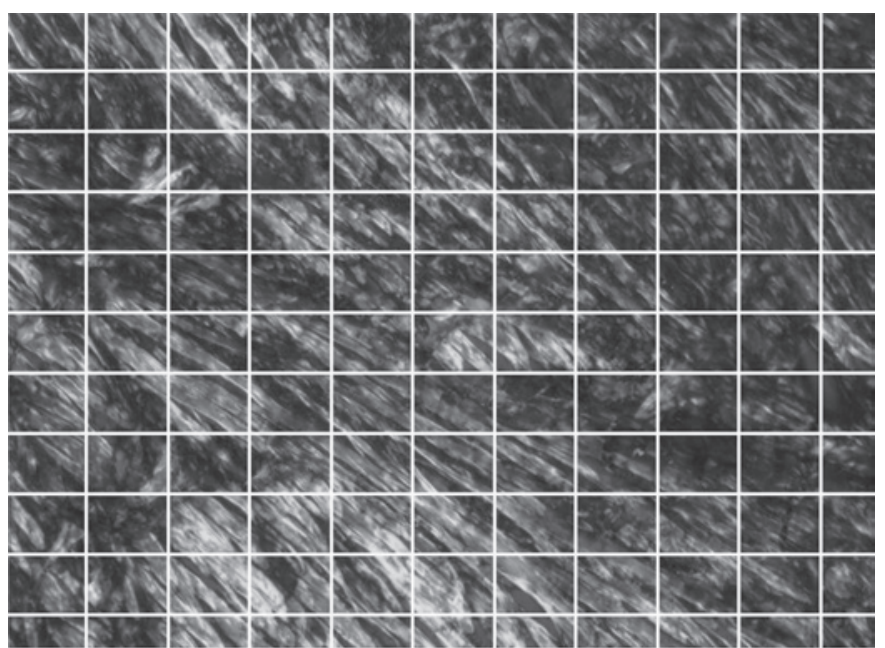

Fig.1. Representação de uma imagem microscópica no Image Pro-plus 4.5, contendo fibras colágenas polarizadas sobrepostas por uma grade com 100 pontos de interseção, utilizando-se objetiva de $10 x$.

As variáveis quantitativas foram submetidas aos testes de Normalidade (Lilliefors) e Homocedasticidade (Cochran) e, posteriormente, à análise de variância. Em caso de significância, foi realizado o teste de Duncan ou de Tuckey, conforme a instabilidade da variável. Quando não atendia às premissas de normalidade e homocesticidade, foram realizadas as transformações apropriadas para posterior análise de variância (Saeg 1999).

\section{RESULTADOS E DISCUSSÃO}

Nos três grupos avaliados, as fibras colágenas apresentaram uma disposição circunferencial, entrelaçadas por fibras orientadas radialmente (Fig.2), conforme foi descrito por Bullough (1970). Essa organização contribui de forma importante para a manutenção de propriedades mecânicas, como força tênsil e rigidez (Paiva 2006). A figura 3 demonstra cortes histológicos dos meniscos corados com HE, sem polarização, representando os três grupos (MF, MG e MR), permitindo a visualização geral do tecido em análise.

Três meniscos (42,8\%) do grupo em glicerina, MG, e um menisco $(14,3 \%)$ do grupo reidratado, MR, apresentaram leve desorganização das fibras em pequenas áreas (Fig.2D, Quadro 1), assim como observado por Guimarães et al. (2007) ao estudarem fibras colágenas de membranas biológicas conservadas em glicerina por 15 dias. Percebe-se, pelos resultados obtidos, que a reidratação em $\mathrm{NaCl}$ 0,9\% favoreceu o restabelecimento da organização e da arquitetura tecidual.

Nos grupos tratados, MG e MR, observou-se retração das fibras colágenas, com maior intensidade no Grupo MG. Esta retração pode influenciar a capacidade do menisco em realizar suas funções mecânicas, já que segundo Paiva (2006) elas dependem de sua estrutura anatômica e de sua propriedade material, que é determinada por sua composição bioquímica, além da interação 

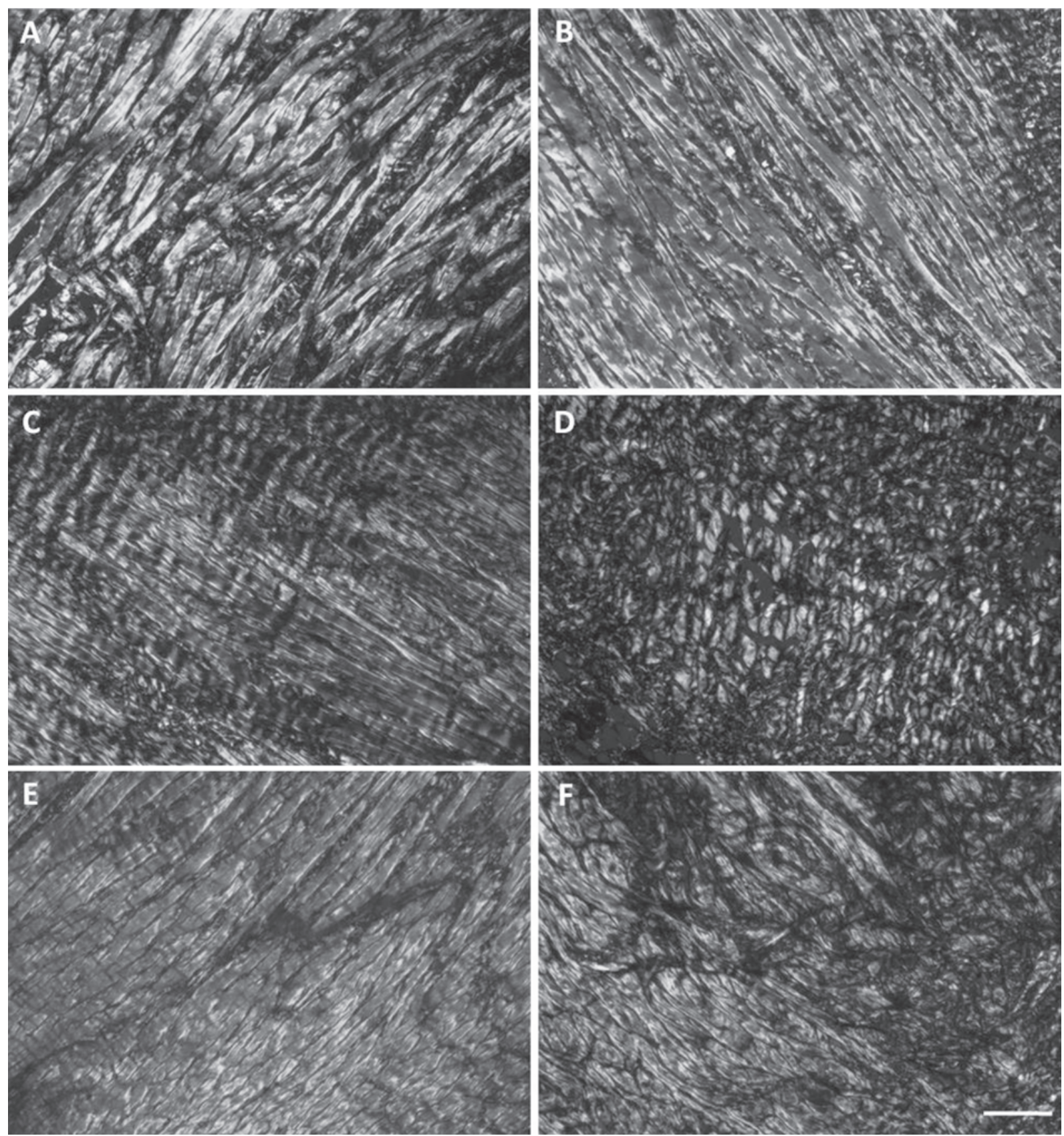

Fig.2. Fibras colágenas observadas em microscópio de luz polarizada. As fibras colágenas Tipo I se apresentam pela coloração amarela, laranja e avermelhada, enquanto as fibras Tipo III estão expressas pela cor verde. Nos três grupos, as fibras Tipo I foram predominantes, apresentando-se entrelaçadas pelas fibras Tipo III (fibrilas). $(\mathbf{A}, \mathbf{B})$ Fibras colágenas dos meniscos do Grupo MF. (C,D) Fibras colágenas dos meniscos do Grupo MG, em D observa-se desorganização das fibras. (E,F) Fibras colágenas dos meniscos do Grupo MR. Picrosirius Red associado à microscopia de polarização. Barra $=20 \mu \mathrm{m}$.

dos seus constituintes como água, proteoglicanos e colágeno.

Por definição, os meniscos são discos fibrocartilaginosos hiperidratados, contendo cerca de $75 \%$ de água (Buma et al. 2004), e foram afetados pela alta concentração osmótica da glicerina $98 \%$, desorganizando, mesmo que parcial e temporariamente, até a reidratação, as fibras colágenas.
A análise da quantidade percentual de fibras colágenas Tipo I e Tipo III (fibrilar) dos meniscos dos diferentes grupos mostrou que houve diferença significativa $(p<0,05)$, entre o grupo controle, MF e os grupos preservados, MG e MR (Quadro 2). O grupo controle apresentou percentual médio de colágeno Tipo I, significativamente menor que os grupos dos meniscos tratados. A média de colágeno Tipo I no grupo controle foi de $77,8 \%$, enquanto nos gru- 
Quadro 1. Distribuição quanto à orientação das fibras colágenas nos três grupos experimentais, meniscos frescos, meniscos em glicerina e meniscos reidratados

\begin{tabular}{cccc}
\hline \multirow{2}{*}{ Menisco } & \multicolumn{3}{c}{ Orientação das fibras colágenas } \\
\cline { 2 - 4 } & $\begin{array}{c}\text { Meniscos } \\
\text { frescos }\end{array}$ & $\begin{array}{c}\text { Meniscos em } \\
\text { glicerina }\end{array}$ & $\begin{array}{c}\text { Meniscos } \\
\text { reidratados }\end{array}$ \\
\hline M-1 & Organizadas & Organizadas & Organizadas \\
M-2 & Organizadas & Organizadas & Organizadas \\
M-3 & Organizadas & Desorganizadas & Organizadas \\
M-4 & Organizadas & Organizadas & Organizadas \\
M-5 & Organizadas & Desorganizadas & Organizadas \\
M-6 & Organizadas & Desorganizadas & Desorganizadas \\
M-7 & Organizadas & Organizadas & Organizadas
\end{tabular}

Quadro 2. Valores médios percentuais e desvios padrão do colágeno tipo I, Tipo III e espaços sem fibras nos três grupos experimentais: meniscos frescos, meniscos preservados em glicerina e meniscos preservados em glicerina e reidratados

\begin{tabular}{cccc}
\hline Grupo & Colágeno Tipo I & Colágeno Tipo III & Espaços sem fibras \\
\hline MF & $77,8 \pm 3,0$ & $14,6 \pm 3,7$ & $7,6 \pm 2,0^{*}$ \\
MG & $84,9 \pm 2,7^{*}$ & $8,5 \pm 2,5^{*}$ & $6,6 \pm 1,2^{*}$ \\
MR & $83,6 \pm 1,2^{*}$ & $10,1 \pm 0,9^{*}$ & $6,3 \pm 0,8^{*}$
\end{tabular}

* As médias não diferem entre si, segundo o teste de Tukey.

pos em glicerina e reidratados foram $84,9 \%$ e $83,6 \%$, respectivamente (Quadro 2).

Os percentuais encontrados foram semelhantes ao citado por McBride \& Clancy (2000) que relataram que o colágeno Tipo I representa cerca de $80 \%$ do conteúdo total de colágeno. Em estudo realizado com meniscos de coelhos, submetidos à temperaturas de $7,2^{\circ} \mathrm{C}$ e $73^{\circ} \mathrm{C}$ negativos por períodos variáveis, o percentual médio de

Fig.3. Fotomicrografias de meniscos. (A) Grupo MF, meniscos frescos: fibras colágenas organizadas, dispostas paralelamente. (B) Grupo MG, meniscos preservados em glicerina: fibras de colágeno organizadas. (C) Grupo MR, meniscos reidratados em solução salina, demonstrando desorganiza-

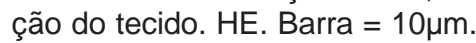

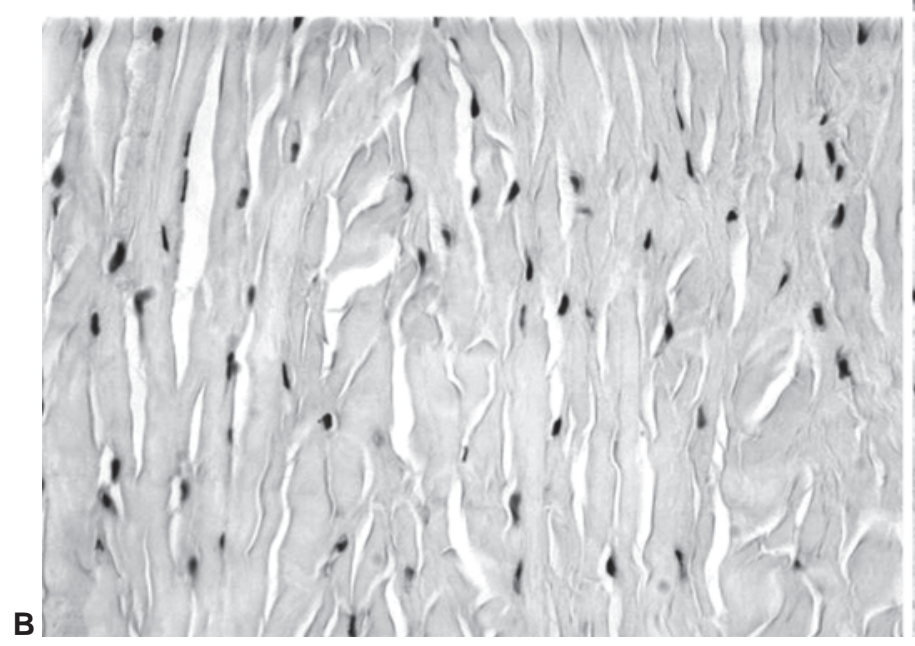

colágeno Tipo I variou de $18,6 \%$ a $27,7 \%$, e $23,7 \%$ a $34,5 \%$, respectivamente (Paiva 2006).

O percentual médio de colágeno Tipo III no grupo controle - MF foi significativamente maior do que nos grupos tratados MG e MR $(p<0,05)$. No grupo controle, a média foi de $14,6 \%$, nos grupos tratados foram $8,5 \%$ nos meniscos em glicerina e 10,1\% nos meniscos reidratados (Quadro 2).

Os locais com coloração preta foram considerados espaços sem fibras colágenas de qualquer tipo. A média de percentagem de espaços sem fibras foi semelhante nos três grupos experimentais (Quadro 2).

A maior concentração de fibras colágenas Tipo I e menor concentração de fibras colágenas Tipo III nos grupos tratados, MG e MR, encontradas neste trabalho, pode ser justificada pela retração das fibras de colágeno. Esta retração das fibras em tecidos preservados em glicerina foi descrita por Guimarães et al. (2007) ao estudarem membranas biológicas preservadas por diferentes períodos. Estes autores relataram que houve retração das fibras colágenas nas amostras preservadas em glicerina. A retração deve-se ao fato da glicerina apresentar acentuada hidrofilia, devido a sua polaridade que, ao tornar-se livre, é capaz de atrair átomos de hidrogênio das molécu-

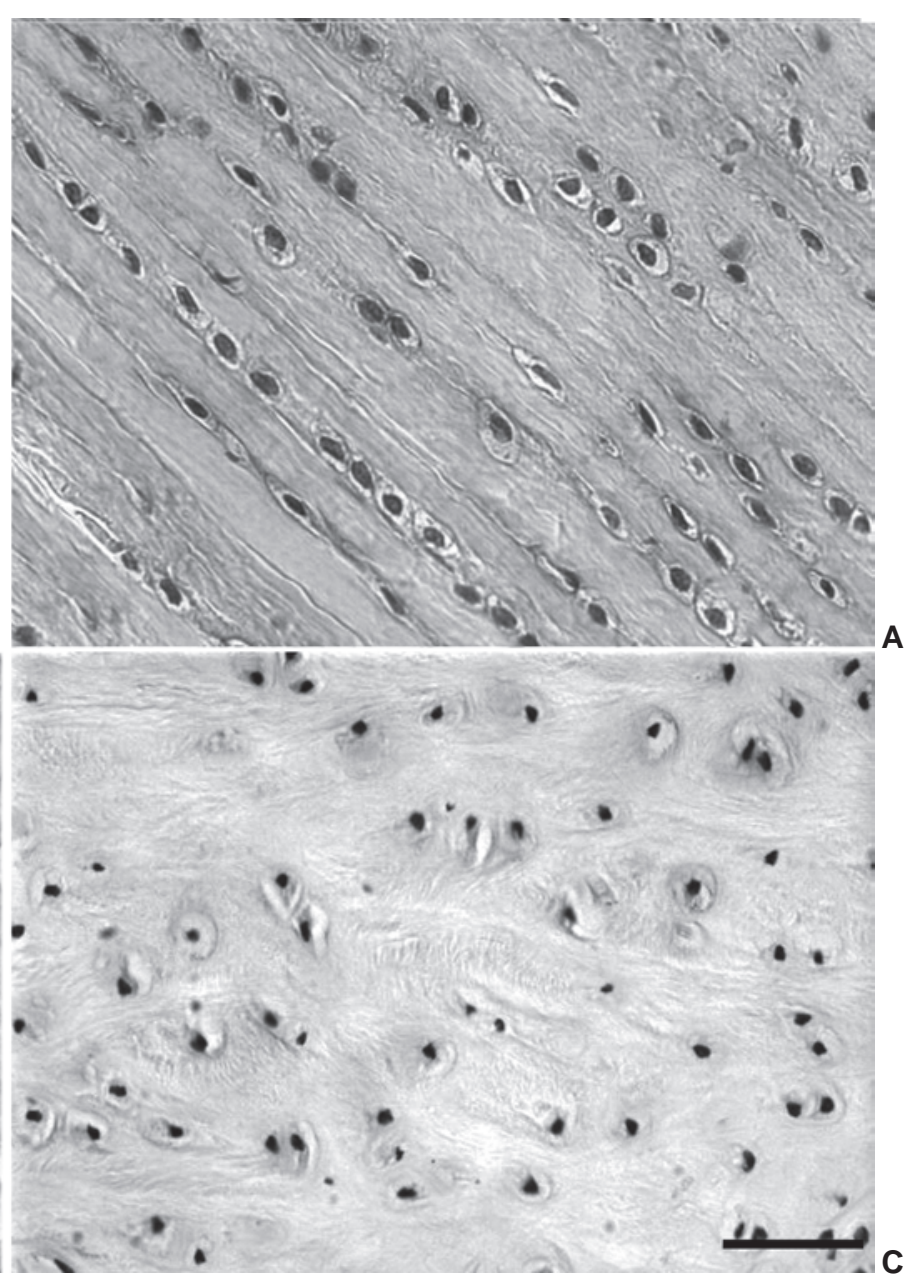




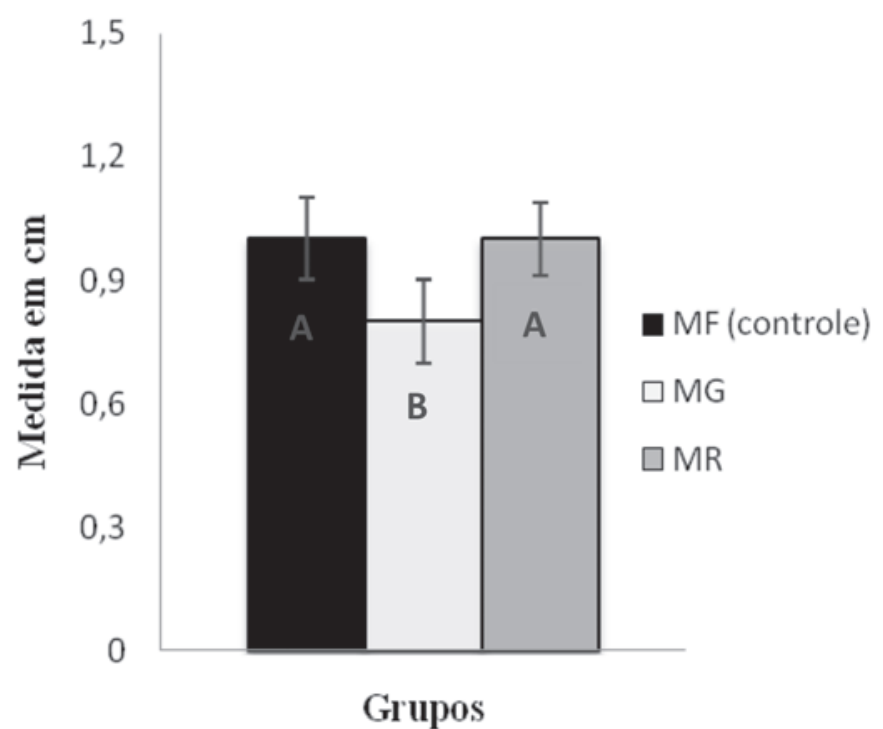

Fig.4. Representação dos valores médios da medida do maior eixo do menisco em $\mathrm{cm}$, observados nos meniscos frescos $(\mathrm{MF})=1,0 \mathrm{~cm}$, meniscos preservados em glicerina $(\mathrm{MG})=$ $0,8 \mathrm{~cm}$ e meniscos preservados em glicerina e reidratados $(\mathrm{MR})=1,0 \mathrm{~cm}$. Tratamentos seguidos de uma mesma letra não diferem entre si ao nível de $5 \%$ de probabilidade.
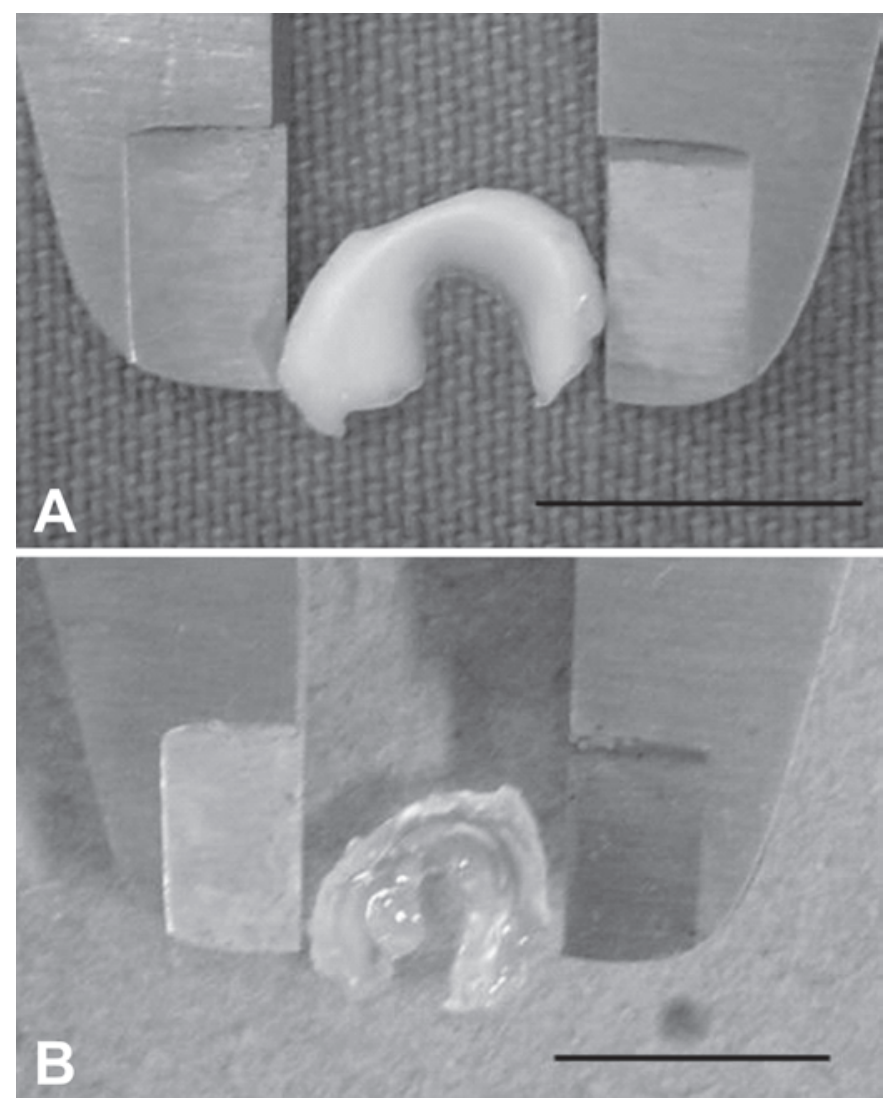

Fig.5. (A) Aspecto macroscópico do menisco após a coleta e (B) após preservação em glicerina 98\% por 30 dias Em (B) o menisco apresenta-se transparente, contraído, rígido e diminuído de tamanho devido à perda de água, quando comparado com o menisco representado em (A). Barras $=1,0 \mathrm{~cm}$. las vizinhas sem, contudo, promover uma reação quími$\mathrm{ca}$, preservando a arquitetura tecidual.

Entende-se que, neste trabalho, a redução no tamanho dos meniscos e a conseqüente retração das fibras colágenas, podem ter feito com que as fibras Tipo I, mais espessas e em maior quantidade, ficassem mais evidentes do que as fibras colágenas Tipo III, que são mais delgadas e frágeis (fibrilas), apresentando-se menos visíveis, reduzindo assim seu percentual nos grupos tratados. A redução do tamanho dos meniscos, após 30 dias submersos em glicerina, pode ser observada na Figura 4.

Os meniscos são fibrocartilagens de coloração esbranquiçada e consistência elástica. Após a preservação em glicerina $98 \%$ os meniscos apresentaram-se transparentes, rígidos e diminuíram de tamanho (Fig.5), devido à perda de água. Segundo Pigossi (1964) a glicerina desidrata o tecido, sem alterar a concentração iônica das células, atuando como eficaz protetor da integridade estrutural do tecido, o que aparentemente, aconteceu nos meniscos deste estudo.

O grupo de meniscos em glicerina apresentou redução significativa $(p<0,05)$ no tamanho em relação ao Grupo MF (Fig.4). Tanto a glicerina quanto a água, moléculas polares, apresentam o fenômeno físico-químico de atração mútua (Pigossi et al. 1971). Este fato promove a condensação do volume caracterizando uma ação desidratante que a rigor consiste em redução de volume exercida pela glicerina nas amostras que nela foram preservadas.

Todos os meniscos do grupo MR voltaram a apresentar o aspecto macroscópico, anterior à preservação e readquiriram tamanho após reidratação sendo que, seis dos sete meniscos que compunham a amostra retornaram ao seu tamanho inicial. O Grupo MR apresentou aumento significativo no tamanho dos meniscos em relação ao Grupo MG, não havendo diferença significativa $(p<0,05)$ entre os tamanhos dos meniscos reidratados e dos meniscos do grupo controle (Fig.4).

A reidratação realizada nos meniscos do Grupo MR não foi suficiente para reverter totalmente a retração das fibras colágenas, mantendo a maior evidência das fibras tipo I que, nesse grupo, apresentaram-se em maior concentração que no Grupo MF. Nos meniscos reidratados, houve uma tendência a redução no percentual médio de colágeno tipo I e aumento do colágeno Tipo III, em relação ao Grupo MG, mas não foram significativos ( $p>0,05)$.

\section{CONCLUSÕES}

Nas condições desse trabalho, conclui-se que a glicerina $98 \%$ não reduz a quantidade de fibras colágenas tipo I, mantém a organização completa das fibras colágenas em $71,4 \%$ dos meniscos e que $85,7 \%$ destes meniscos retornam ao seu tamanho inicial, após reidratação.

A glicerina é eficaz na preservação de meniscos mantendo o tamanho do menisco e a percentagem do colágeno semelhante à de meniscos frescos. 


\section{REFERÊNCIAS}

Alvarenga J. 1992. Possibilidades e limitações da utilização de membranas biológicas preservadas em cirurgia, p.33-42. In: Daleck C.R., Baptista L.C. \& Mukai L.S. (Eds), Tópicos em Cirurgia de Cães e Gatos. Jaboticabal, SP.

Arnoczky S.P. 1996. Patomecânica das lesões do ligamento cruzado e meniscos, p.889-902. In: Bojrab M.J. (Ed.), Mecanismos da Moléstia na Cirurgia dos Pequenos Animais. Manole, São Paulo.

Bullough P.G., Munuera L., Murphy J. \& Weinstein A.M. 1970. The strength of the menisci of the knee as it relates to their fine structure. J. Bone Joint Surg. 52B(3):564-570.

Buma P., Ramrattan N.N., Van Tienen T.G. \& Veth R.P.H. 2004. Tissue engineering of the meniscus. Biomaterials 25(9):1523-1532.

De Groott J.H., De Vrijer R., Pennings A.J. \& Jansen H.W.B. 1996. Use of polyurethanes for meniscal reconstruction and meniscal prostheses. Biomaterials 17(2):163-173.

Del Carlo R.J., Galvão S.R., Viloria M.I.V., Souza T.D. \& Filho A.M. 1999. Aloenxertos ósseos caninos diferentemente preservados. Revta Bras. Ciênc. Vet. 6(3):121-126.

Filgueiras R.R., Del Carlo R.J., Viloria M.I.V., Odenthal M.E., Lavor M.S.L. \& Duarte T.S. 2007. Aloenxerto ósseo, preservado em glicerina, na reconstrução isquiopúbica após acesso ventral à cavidade pélvica de cadelas. Revta Ceres 51(298):719-728.

Guimarães G.C., Scavone A.R.F., Machado M.R.F., Cruz C., Capalbo A.C. \& Santos A.L.Q. 2007. Avaliação histológica de membranas biológicas bovinas conservadas em glicerina e a fresco. Bioscience $\mathrm{J}$. 23(3):120-127.

Hulse D.A. \& Johnson A.L. 2002. Tratamento da doença articular, p.10761077. In: Fossum T.W. (Ed.), Cirurgia de Pequenos Animais. Rocca, São Paulo.

Jackson J., Vasseur P.B., Griffey S., Walls C.M. \& Kass P.H. 2001. Pathologic changes in grossly normal menisci in dogs with rupture of the cranial cruciate ligament. J. Am. Vet. Med. Assoc. 218(8):12811284.
McBride D.G. \& Clancy Jr W.G. 2000. Lacerações meniscais/reparação, p.270-278. In: Andrews J.R. \& Timmerman L.A. (Eds), Artroscopia: Diagnóstico e cirurgia. Revinter, Rio de Janeiro.

McDevitt C.A. \& Webber R.J. 1990. The ultrastructure and biochemistry of meniscal cartilage. Clin. Orthop. Related Res. 252:8-18.

Paiva V.C. 2006. A Correlação entre diferentes temperaturas e períodos de preservação sobre as fibras colágenas de meniscos de coeIhos. Dissertação de Mestrado em Cirurgia e Experimentação, Escola Paulista de Medicina, USP, São Paulo. 48p.

Pigossi N. 1964. Implantação de dura-máter homóloga conservada em glicerina. Estudo experimental em cães. Dissertação de Doutorado, Faculdade de Medicina, USP, São Paulo. 92p.

Pigossi N. 1967. Glicerina na conservação de dura-máter: estudo experimental. Dissertação de Livre Docência, USP, São Paulo, SP.

Pigossi N., Raia A., Lex A., Gama A.H., Simonsen O., Haddad J., Stolf N., Zerbini E.J., Miniti A. \& Tenuto R. 1971. Estudo experimental sobre o emprego, como implante, da duramáter homógena conservada em glicerina à temperatura ambiente. Rev. Assoc. Med. Bras. 17(8): 263-278.

Rijk P.C. 2004. Meniscal allograft transplantation. Part I. Background, results, graft Selection and preservation, and surgical considerations. Arthroscopy 20(7):728-743.

Saeg 1999. Sistema para análises estatísticas e genéticas. Versão 8.1. Fundação Arthur Bernardes, Universidade Federal de Viçosa, Viçosa, MG.

Somer L. \& Somer T. 1983. Is the meniscus of the knee joint a fibrocartilage? Acta Anatomica 116(3):234-244.

Torres B.B.J., Muzzi L.A.L., Muzzi R.A.L. \& Valério A.G. 2006. Como proceder nas lesões meniscais em cães: revisão. Clin. Vet. (63):4858.

Vasseur P.B. 2007 Articulação do joelho, p.2090-2115. In: Slatter D. (Ed.), Manual de Cirurgia de Pequenos Animais. Vol.2. Manole, São Paulo. 